\title{
LAS RELACIONES ENTRE NÁPOLES Y LA SANTA SEDE EN LA CORRESPONDENCIA DEL CARDENAL TORRIGIANI CON EL NUNCIO DE ESPAÑA (1758-1762)
}

\author{
Ana SÁNCHEZ MONTAHUD
}

Universidad de Alicante

\begin{abstract}
Resumen
En un momento en el que las relaciones entre Nápoles y Roma presentaban una gran complejidad, la correspondencia del Secretario de Estado del Vaticano, cardenal Torrigiani, y el nuncio en España permite distinguir los temas que preocuparon a la Santa Sede durante el pontificado de Clemente XIII.
\end{abstract}

\begin{abstract}
In a moment in which the relations between Naples and Rome were of great complexity, the correspondence between the State Secretary of the Vatican, Cardinal Torrigiani, and the nuncio in Spain allows us to distinguish the topics that concerned to the Papal seat during the reign of Clement XIII.
\end{abstract}

Ningún otro territorio de Europa ha sido gobernado por tan variada sucesión de dinastías extranjeras como Nápoles. En 1734, tras haber sido regida por más de dos siglos por España y Austria, Nápoles se convirtió en la capital de un reino independiente. Carlos de Borbón venció a las tropas austriacas, y ocupó el trono con el nombre de Carlos VII. Y así, Nápoles junto a Sicilia, formó un vasto reino meridional destinado a perdurar hasta 1860: Reino de las Dos Sicilias.

Enseguida se observaron las ventajas de la independencia y se obtuvieron grandes progresos. Carlos se apoyó en un grupo de hombres de cultura y experiencia. Entre éstos destacó Bernardo Tanucci, secretario de Estado entre otras atribuciones, y el principal impulsor de las tentativas de reforma del reino.

Pero era difícil acabar con instituciones y hábitos profundamente arraigados. Y, sobre todo, desde el momento en que Tanucci y sus colaboradores se inclinaron por una política anticurialista, vieron alzarse ante ellos a la Santa Sede como un poderoso 
enemigo, ya que Roma no dudó en utilizar todos los medios a su alcance para defender sus derechos en el reino.

Además, se debe tener en cuenta que el pontificado de Clemente XIII con su Secretario de Estado Torrigiani, supuso un notable giro hacia el conservadurismo. No estaban, por tanto, dispuestos a tolerar ningún intento de las monarquías católicas por sacudirse su tutela, si bien desde el punto de vista dogmático nunca se discutió la supremacía romana.

La correspondencia del Secretario de Estado Vaticano, cardenal Torrigiani, con el nuncio apostólico en España, ofrece un cuadro vivo de las relaciones europeas de mediados del Setecientos. Y el Reino de Nápoles, por múltiples razones, ocupó amplio espacio en su epistolario.

\section{I}

El cardenal Luigi Maria Torrigiani fue nombrado Secretario de Estado Vaticano por Clemente XIII en octubre de $1758^{\prime}$. A diferencia de su antecesor en el cargo ${ }^{2}$ demostró enseguida que era un hombre de carácter y un firme defensor de los derechos de la Santa Sede. En la determinación por llevar a cabo sus propósitos, no tardó en enfrentarse abiertamente a las cortes católicas europeas, impregnadas del regalismo enfervorizado del siglo XVIII.

Lógicamente, una de las funciones del Secretario de Estado era la de mantener una comunicación fluida y constante con las distintas Nunciaturas existentes en los países católicos. España, por supuesto, no iba a ser una excepción. Y Torrigiani, a pesar de las limitaciones propias de la época, estuvo en contacto permanente con los distintos Nuncios que ocuparon el cargo en Madrid ${ }^{3}$.

Esta copiosa correspondencia del cardenal Secretario ${ }^{4}$ ofrece una visión interesante de la situación política y social europea, ya que los asuntos tratados en ella muestran las preocupaciones de la Santa Sede en sus relaciones con los distintos mo-

1. Luigi Torrigiani nació en Florencia el 18 de octubre de 1697 , y fue creado cardenal por Benedicto XIV el 26 de noviembre de 1753. Wall decía a Roda (16-XI-1760) que «era de genio fuerte, casi insolente. No atendía que su ministerio principal era serlo del Vicario de Cristo; se imaginaba serlo del rey de Prusia y obligaría al Papa a la guerra para defender derechos y posesiones», en DANVILA, M. Reinado de Carlos III, tomo II, pp. 222-223). Murió el 6 de enero de 1777, y fue sepultado en la iglesia de San Giovanni dei Fiorentini en Roma.

2. Alberico Archinto, fallecido en Roma el 30 de septiembre de 1758, fue nuncio apostólico en Florencia y Varsovia. En 1756 fue nombrado cardenal y el 31 de agosto sucedió como Secretario de Estado a Valenti Gonzaga. Después de su muerte, y tras un breve período con el cardenal Guidobono Cavalchini, el 6 de octubre de 1758, se otorgó el cargo de Secretario a Luigi Torrigiani. Consiguió que Benedicto XIV firmase el 1 de abril de 1758 el breve de reforma de la Compañía de Jesús en Portugal. Vid. VV.AA., Bernardo Tanucci. Epistolario, 1985, Tomo V, p. 433.

3. En el período del pontificado de Clemente XIII, ejercieron la labor de Nuncio los Monseñores Girolamo Spínola, hasta el 20 de julio de 1760, y Lazzaro Opizio Pallavicini, anterior Nuncio en Nápoles.

4. La documentación se encuentra en Archivio Segreto Vaticano, Segreteria di Stato, Sezione Spagna, volúmenes 431,432 y 433 . 
narcas. Relaciones que, como veremos en el caso particular de Nápoles, estaban lejos de ser pacíficas y exentas de sobresaltos.

Ante el vacío de poder producido en España durante la enfermedad y posterior fallecimiento de Fernando VI, don Carlos se convertía de hecho y de derecho en el nuevo rey. Y para ello, se veía obligado a renunciar a Nápoles.

El problema de la sucesión se trasladaba ahora a los Dos Sicilias. El primogénito de don Carlos, el Infante Felipe Pascual de doce años, estaba incapacitado física y mentalmente para gobernar. Ante este hecho fue oficialmente inhabilitado. Al segundo hijo varón, el Infante don Carlos, se le asignó la condición de heredero al trono español, y al tercero, el Infante don Fernando, lo nombró el monarca sucesor suyo en Nápoles ${ }^{5}$. Debido a su minoría de edad, don Fernando estaría bajo la tutela del Consejo de Regencia, verdadero órgano de gobierno, y sobre todo, de su personalidad más relevante, Bernardo Tanucci.

Este importantísimo cambio, lejos de irritar a las restantes monarquías europeas, les pareció oportuno ${ }^{6}$. Pero la Santa Sede no podía dejar de mirar con cautela y precaución que el papel de Tanucci se convirtiera en determinante dentro del gobierno napolitano. En realidad, no era de extrañar la reserva de Roma ante un hombre que escribía:

«Non è stato bastante Gesù Cristo ad abolir la superbia, la rapacità, la furberia sacerdotale. Roma ha saltato sul corpo di Gesù Cristo e degli Apostoli, per vestirsi di sinagoga, e di quanto altro ha il gentilesimo teologo saputo inventare per usurpare beni e giurisdizione»? .

Clemente XIII había encontrado su apoyo más firme en el Secretario de Estado Torrigiani el cual, ante la debilidad de carácter del pontífice, se ocupaba de dirigir la política vaticana ${ }^{8}$.

La lucha contra la Curia romana fue muy activa en los primeros años de la Regencia napolitana. Y estas acciones anticuriales emprendidas en Nápoles por su ministerio (sobre todo, por Tanucci) aparecieron de forma inmediata en la correspondencia del cardenal Torrigiani con los nuncios de España. El motivo era claro: Torrigiani sabía que el nuncio era una eficaz herramienta ante Carlos III. Era el canal que debía utilizar para intentar frenar, con la intervención del monarca español, las continuas afrentas que la Santa Sede y los eclesiásticos soportaban en Nápoles.

5. OLAECHEA, R. «La diplomacia de Carlos III en Italia» en Revista de Historia Moderna. Anales de la Universidad de Alicante, número 8-9, Alicante, 1988-1990, p. 163.

6. Las principales potencias en guerra, Gran Bretaña, el Imperio y Francia, deseaban complacer al nuevo monarca, que podía ejercer como árbitro de la compleja situación internacional del momento.

7. Tanucci a Galiani, Caserta, 28 de febrero de 1767 en Lettere inedite... cit. en Arch. stor. prov. nap., XXX, 1905, p. 435 en MINCUZZI, R., Bernardo Tanucci, ministro di Ferdinando di Borbone 17591776, Bari, 1967, p. 43.

8. Sobre el carácter del Papa Rezzonico y su relación con Torrigiani, se pueden observar las siguientes palabras de Tanucci: «Il povero Papa ha poco cervello, si lascia conduir pel naso da Torrigiani, dal nipote, e dai Gesuiti...». Tanucci a Jacci, 1760, en VV.AA. Bernardo Tanucci. Epistolario, p. 59. 
En los primeros años de su Secretaría, la correspondencia de Torrigiani con el nuncio en Madrid se centró en la partida desde Nápoles del futuro Carlos III de España. Este hecho provocaba una lógica inquietud a Roma que deseaba conocer con exactitud los cambios que se producirían en ambos reinos:

$\ll \ldots$ se ha entendido el sistema con el que se regulará internamente la Regencia... Se desea ahora saber cómo viene tomado por los españoles de la vieja escuela el juicio que actualmente pende en Nápoles sobre la designación de un Príncipe de Asturias diferente del que según el orden natural debería ser reconocido como tal... Muchísimos son los capítulos de problemas versados entre nuestra Corte y la de Nápoles. Es imposible arreglarlos porque no valen tratados, no valen razones, con quien fomenta principios y máximas, de las cuales no encontrará ciertamente peores allí en el ánimo de algún ministro el nuevo monarca, cuya piedad ha sido el escudo mejor que hemos tenido contra los atentados del ministerio...»9.

Torrigiani, por tanto, veía de forma clara que la partida de Carlos a España no haría más que perjudicar las ya tirantes relaciones con Nápoles. Las informaciones del Nuncio en España pasaban a tener un valor vital:

«Como con el Reino de Nápoles siempre se teme que puedan surgir nuevas disputas, como ya desgraciadamente van germinando, y viéndose que en el futuro los asuntos más graves de Nápoles dependerán de la decisión de la Corte de España, así podrá también Vuestra Excelencia [el Nuncio] de la mejor manera fomentar las buenas intenciones del monarca y procurar la benevolencia de los principales ministros. Esto será mucho más necesario si sucede lo que Vuestra Excelencia me dice en sus números del 25 de septiembre, es decir que a la llegada del rey no faltará quien le llegue proponiendo novedades perjudiciales para nosotros. Se contentará Vuestra Excelencia con explicarse mejor en este punto, y con hacerme conocer cuáles pueden ser estas novedades y los fundamentos con que se conjeturas ${ }^{10}$.

En 1760, Nápoles seguía siendo el centro de atención del Secretario. Torrigiani informaba al Nuncio Spinola del pleito que mantenía un noble napolitano, el barón de Bitetto, con la Cámara Apostólica ". Este suceso, que en apariencia podía parecer trivial, dio lugar a un verdadero conflicto jurisdiccional. El barón se dirigió primero a los Tribunales napolitanos. Torrigiani, inquieto, ordenó al Nuncio que presionase al rey Carlos a fin de que apoyase una decisión favorable a la Cámara Apostólica, absolviéndola del pago de la deuda. Estaba en juego el prestigio de la Santa Sede. Pero

9. Archivio Segreto Vaticano (ASV), Segreteria di Stato, Spagna, vol. 431, Torrigiani al Nuncio, Roma 6 de septiembre de 1759. Traducción propia. Es destacable la consideración del monarca como único bastión defensivo ante los ataques de un ministerio enemigo de la Santa Sede.

10. ASV, Ibidem.

11. El barón de Bitetto era Biagio di Noía. Bitetto pedía la liquidación de una deuda contraída con él por Monseñor Clarelli, presidente de la «Grascia» de Roma, a cuenta de la referida Cámara Apostólica. En concreto, la deuda era por haber suministrado en 1748 aceite al Monseñor (cit. en MAIORINI, M.G., Bernardo Tanucci. Epistolario, vol. IX, Roma, 1985, p. 316). 
la causa de Bitetto no se solucionó en este momento, y Torrigiani pensó que sus temores estaban justificados. No dejaría Nápoles pasar ninguna ocasión para atacarles.

A esto, se debe añadir el constante menoscabo que sufría el patrimonio eclesiástico a favor del real en el reino napolitano. De esta forma, el poder económico de la Iglesia disminuía, así como su influencia social. Acabar con las denominadas «manos muertas» se convirtieron en uno de los objetivos principales de la política de Tanucci. Y los medios para conseguirlo contemplaban desde la integración de las propiedades en el patrimonio real como otros más audaces, como la desamortización. En este sentido, el caso de la abadía de La Bagnara ${ }^{12}$ estaba en el centro de la disputa entre la Santa Sede y el reino de Nápoles. Según cuenta el propio Secretario al Nuncio en España:

«La Abadía de la Bagnara en el Reino de Nápoles tras varias vicisitudes perteneció varios siglos a los religiosos dominicos con la jurisdicción casi episcopal ejercida por el prior «pro tempore» de ese convento. El año pasado, los ministros reales la consideraron patronato real y solicitaron a la Dataría que se enviaran las bulas a un tal abad Cristiani nombrado por Su Majestad; se tuvo dificultad para ponerse de acuerdo, no tanto por el perjuicio, como por otras importantísimas razones... de repente se supo que se había expulsado a los religiosos de dicha abadía y que a través del obispo de Cefalú no sólo se había nombrado al citado abad Cristiani, sino que se le había investido de la jurisdicción con la cual... ha cometido con escándalo universal de los pueblos vecinos y con deplorable perjuicio a las almas de los habitantes de ese territorio» ${ }^{13}$.

Roma no podía permanecer impasible ante este nuevo ataque y como refería Torrigiani, se envió un breve al obispo de Cefalú para amonestarle por su actuación. Este breve fue considerado por Tanucci como «una de las habituales insolencias de la Corte de Roma» ${ }^{14}$. El Nuncio debía en esta ocasión procurar que la queja de Tanucci no influyera en la Corte española, a la que el Reino de Nápoles comunicaba todas sus acciones. En estos delicados momentos se produjo un cambio en la Nunciatura. Con fecha del 17 de julio de 1760, aparece la primera carta escrita por Torrigiani al nuevo Nuncio Apostólico en Madrid, Monseñor Pallavicini, Arzobispo de Lepanto. Pero no por esto, Nápoles dejaba de importunar a la Santa Sede.

En efecto, el asunto de Bitetto se alargaba y la Regencia napolitana aprovechó la ocasión para manifestar su disgusto con la Cámara Apostólica. Solicitó, además, ser informada para decidir rápidamente en el contencioso. El rey de España prefería mostrarse en esta causa en una posición neutral por no aumentar los problemas con Roma. Tras pasar la causa a distintos tribunales (Tribunal del Comercio de Nápoles, Cámara Real napolitana) se trasladó a los tribunales romanos. Pero los manejos del cardenal Orsini, que insinuaba que era un procedimiento irregular que el Papa recibiera en audiencia al barón para facilitar la resolución del caso, no provocaba en Torrigiani gran optimismo ${ }^{15}$.

12. ASV, Op. cit., cifra del 2 de abril de 1760 .

13. ASV, Op. cit., cifra del 2 de abril de 1760. Traducción propia.

14. ASV, Op. cit., cifra del 8 de mayo de 1760.

15. ASV, Op. cit., cifra del 26 de noviembre de 1761. El cardenal Orsini, duque de Gravina, era el embajador napolitano en Roma. 
Por si fueran pocos los problemas, otra cuestión aparecía ensombreciendo la situación. Las relaciones napolitanas con Roma en 1759 fueron tan tensas que Clemente XIII llegó a decir a Orsini que «ningún soberano reconocería al rey Fernando» ${ }^{16}$. Pero a pesar de esto, Tanucci consiguió que se redactara una investidura para el joven monarca diferente a las anteriores y sin fórmulas feudales a Roma. Torrigiani se lamentaba en su cifra del 11 de junio de 1761.

«Entre las grandes preocupaciones del Pontificado en los tiempos presentes y entre las muchísimas molestias, que recibe Su Santidad por los asuntos de Nápoles, no faltaba más que se atentase contra los derechos de la Santa Sede sobre el referido reino. Encontrará Vuestra Ilustrísima una memoria, en la que se expuso la causa del disgusto pontificio, y encontrará rápidamente el agravio intolerable que recibe la Santa Sede por la «Reversale» o Bula de Oro que el Reino de Nápoles manda a Nuestro Señor. Se trata de un reino que por muchos siglos ha sido feudo de la Iglesia de Roma, y como tal reconocido por tantos soberanos, y por el mismo rey de España, y es más también por el mismo rey de Nápoles que ha pedido y recibido la investidura. No puede... Su Santidad... buscando conservar los derechos de la Santa Sede, descuidar la injuria manifiesta que se le hace con la variación de la Reversale» ${ }^{17}$.

Continuaba escribiendo el Secretario que sólo se pedía que se siguiera observando lo que hizo Su Majestad Católica cuando recibió la investidura de Clemente XIII. El Rey Fernando no debía alejarse del ejemplo de su padre. El nuncio en Madrid recibió instrucciones para presentar una queja al rey español porque «si no se arregla la acción de la Regencia al renovar la «Reversale», el derecho de la Investidura, el censo, en resumen, el Reino de Nápoles se perderá para siempre para la Iglesia Romana» ${ }^{18}$.

El regalismo napolitano se sentía crecido también por el asunto del Visitador Apostólico en Córcega ${ }^{19}$. La sensación de fuerza llevó a Tanucci a acariciar la idea de declarar de Patronato Real muchas abadías del reino dadas en encomienda a prelados de la Curia romana. Pero será la publicación en Nápoles del llamado Catecismo de Mesènguy, auspiciada por Tanucci y Bottari, lo que provocó el enfrentamiento más profundo entre Nápoles y la Santa Sede ${ }^{20}$.

16. Nápoles, 4 de diciembre de 1759, A.G.S., libro 236, c. cit. en MINCUZZI, R. Op. cit., p. 46.

17. ASV, Segretaria di Stato, Spagna, vol. 431. Traducción propia. Cifra del 11 de junio de 1761 .

18. Ibídem.

19. La isla de Córcega pertenecía a la república de Génova. Desde 1755 el movimiento independentista, con Pascuale Paoli al frente, se había hecho con el control de la mayor parte de la isla y los obispos habían sido desterrados por considerarse partidarios de Génova. Clemente XIII nombró un Visitador Apostólico. Paoli le recibió peto la República protestó y publicó un edicto ofreciendo una recompensa al que lo apresase. Roma declaró nulo el edicto (15 de mayo de 1760) y envió un breve de protesta a Génova (17 de mayo). El rey de Nápoles se ofreció como mediador, si bien la contienda perduró hasta el fin del dominio genovés sobre Córcega (1768). Cit. en BARRIO, M. Carlos III. Cartas a Tanucci (1759-1763), 1988, p. 18. Referencias a la cuestión corsa en ASV, Op. cit., cifra del 18 de junio de 1761 o la del 30 de julio de 1761 .

20. Giovanni Gaetano Bottari (1698-1775) fue llamado a Roma por Clemente XII en 1730. Fue bibliotecario de la Corsiniana. En 1731 enseñó escuela eclesiástica y desde 1735, fue capellán secreto del Papa. En 1768, era prefecto de la Biblioteca Vaticana. Fue el perfecto representante del jansenismo romano, y había establecido (desde 1758) una interesante correspondencia con el ministro Tanucci. 
La traducción se llevó a cabo entre 1758 y 1760 . En el libro se negaba la infalibilidad del Papa y se atacaba a los jesuitas. Ya había sido condenado dos veces en el anterior pontificado. Pero a pesar de esto, se encargó la traducción a Cantagalli y se publicó en Nápoles con el título Esposizione della dottrina cristiana.

La edición napolitana se imprimió con la aprobación del arzobispo de Nápoles, cardenal Sersale ${ }^{21}$ y las reacciones en contra de la obra no tardaron en aparecer. Como escribió Tanucci:

«... sento li scompigli e il fuoco che suscitano contro il santo, e savio libro dell'Esposizione della dottrina cristiana stampata qui coll'approvazione di questo cardinale arcivescovo» ${ }^{22}$.

Clemente XIII, movido por las quejas de los jesuitas, protestó ante la Corte napolitana y nombró una comisión de diez teólogos para examinarla ${ }^{23}$. La obra se prohibió el 28 de mayo de 1761. El Papa, con el breve del 14 de junio, condenó el Catecismo en todas las lenguas y ediciones, enviando junto al breve a los obispos una encíclica aconsejando el uso del Catecismo romano. Pero el indudable triunfo de los jesuitas en Roma se acompañó de una gran derrota en otras cortes. Venecia, Turín, Milán, Francia, España y, por supuesto, Nápoles, rechazaron el breve. Torrigiani observaba inquieto la radicalización del caso del Catecismo, como demuestra la lectura de su correspondencia con el nuncio en Madrid. Y muy sorprendente es el siguiente párrafo, escrito a Pallavicini tras los hechos ocurridos en Madrid en relación con la obra:

«... lo que ahora tiene a Nuestro Señor en la mayor preocupación es la consulta que hará la Cámara de Castilla sobre el ejercicio de las facultades del tribunal de la Inquisición y de la Nunciatura. Es de esperar que la consulta sea moderada por el debate profundo... Si la cosa se hubiese tenido que examinar en la Cámara de Santa Clara, no habría tardado ni un momento en estallar el rayo más terrible, pues usted se debe dar cuenta de la diversidad que hay entre las máximas de Nápoles y las de España. Los obispos de estos reinos son de otro crédito y de otro pecho que los de Nápoles.... ${ }^{24}$.

El asunto del Catecismo, lejos de arreglarse, presentaba cada vez un aspecto más sombrío. En Nápoles, no se dejaba de hostigar a la Santa Sede. Torrigiani lo explicaba así:

«Otro estrepitoso accidente ha estado a punto de ocurrir en Nápoles, por lo que Nuestro Señor hubiera tenido que declarar su resentimiento. Ya sabrá Vuestra Ilustrísima de la

21. El cardenal Antonio Sersale, natural de Sorrento, era arzobispo de Nápoles desde 1754.

22. MAIORINI, M.G. Bernardo Tanucci. Epistolario, Carta dirigida a Orsini, p. 447.

23. Tanucci escribía a Wall el 9 de junio de 1661: «Avrà V.E. saputo dal buon Roda che sette sono stati li voti dei cardinali per la proibizione del catechismo, e cinque per la permissone. Li cinque erano li più dotti e riguardevoli, cioè Spinelli, Orsi, Galli, Passionei, Tamburini, che diede il voto al Papa prima di cader infermo, e perciò non si conta nella Congregazione, oltre Corsini; li sette sono conosciuti più per la politica che per la teologia» (MAIORINI, M.G., Op. cit. pp. 723-724).

24. ASV, Segreteria di Spagna, Sezione Spagna, vol. 431, cifra del 15 de octubre de 1761. Traducción propia. 
consulta que hizo el señor marqués Fraggianni contra la Encíclica y el Breve de Nuestro Señor prohibitivo del conocido Catecismo. Esta consulta es uno de los más insolentes, temerarios y falsos escritos que pueden nunca salir a la luz. Junto a la consulta, circulaba también una Pragmática... y siempre hemos disimulado y callado. Pero cuando se supo con seguridad por monseñor Nuncio en Nápoles que se iba a publicar en las imprentas por orden real, se quejó personalmente y por escrito a los señores de la Regencia y se obtuvo la suspensión de la referida impresión. El señor marqués Tanucci se ha mostrado contrario a esta suspensión.» ${ }^{25}$.

Torrigiani, cada vez más desesperado, solicitaba al Nuncio en Madrid la máxima celeridad en sus gestiones:

«Debo con la mayor premura recordar a Vuestra Ilustrísima la representación que le encargué para impedir que desde allí [España] se dé la orden a Nápoles para publicar la conocida Pragmática contra el Breve y la Encíclica de Nuestro Señor. Estoy seguro de que si el Rey de Cerdeña ${ }^{26}$ no da esta orden, no verá la luz en Nápoles la impresión de esta injuriosa ley ... ${ }^{27}$.

Desde luego, en España las cosas no habían discurrido tampoco de forma favorable para Roma. Aprovechando la ocasión, Carlos III promulgó un real decreto el 20 de noviembre de 1761, elevado a pragmática sanción el 18 de enero de 1762, por el que se estableció el exequatur regium. La repercusión de esta medida en la corte de Nápoles fue considerable. Tanucci fue informado por Wall ${ }^{28}$ de la resolución del Rey Católico. Las consecuencias se dejaron sentir inmediatamente:

«... ni la impresión ni la pragmática han tenido efecto. Sin embargo, sí está bien acabada una carta circular del marqués Fraggianni, enviada a todos los obispos del reino... He aquí el fruto de las nuevas órdenes de España. Cuando monseñor nuncio denunció personalmente y por escrito a los señores de la Regencia la irregularidad de mandar a los obispos publicar el escrito y de querer sujetar a las formalidades del exequatur las bulas y breves doctrinales del Papa... ha respondido que en vista de lo que en España se había determinado, debían también ellos uniformarse a las reglas que se habían establecido allí (en España] ${ }^{20}$.

Incluso en la citada cifra, ya se relataba cómo utilizando el regium exequatur se había negado al cardenal arzobispo de Nápoles la licencia para efectuar la impresión del calendario para la ciudad. El motivo era que, «en dicho calendario estaba anotado bajo el Jueves Santo que se debía hacer la publicación de la bula In Coena Domini y en el día de San Gregorio VII se habían previsto las lecciones propias... Si se sigue con este método veremos... arruinado todo el derecho canónico porque ninguna de es-

25. ASV, Ibidem, cifra del 19 de noviembre de 1761. Traducción propia. Nicola Fraggianni (1686-1763) era consejero de Santa Chiara y Delegado de la Real Jurisdicción. Su cultura y preparación, junto a su anticurialismo, le hizo ser gran colaborador de Tanucci. Aunque éste último desconfiaba de él, principalmente porque lo consideraba filoaustriaco.

26. Escrito al margen: «España».

27. ASV, Ibidem, cifra del 3 de diciembre de 1761.

28. AGS, Estado, leg. 6092. Buen Retiro, 6 de noviembre de 1761.

29. ASV, Segreteria di Stato, Sezione Spagna, vol. 431. Cifra del 7 de enero de 1762. 
tas leyes ha sufrido el exequatur; es más, habiéndose introducido el exequatur desde hace alrededor de siglo y medio, todo lo que es anterior a este tiempo no tendrá categoría de ley y no merecerá que sea observado y ejecutado... ${ }^{30}$.

Pero no acababan aquí las «insolencias» de la Regencia de Nápoles. Varias abadías (Sgurgola, Real Valle, Santísima Trinidad) trataban de ser incorporadas al Patrimonio Real ${ }^{31}$, y a esta serie de pleitos con Roma se vino añadir en 1762 el asunto Pagliarini.

El librero e impresor Pagliarini había sido detenido en Roma en 1760. Toda clase de rumores se habían extendido sobre el motivo de dicho encarcelamiento en las mazmorras de la Inquisición. Se hablaba que tenía en su poder libros prohibidos. Otros rumores le apuntaban como el impresor de las Reflexiones de un portugués sobre el memorial presentado por los PP jesuitas... (1758) y el Apéndice a las reflexiones... (1760). E, incluso, se le imputaba la impresión de I lupi smascherati... (1761), terrible ataque a los cardenales romanos y a la Compañía de Jesús. Las impresiones de los libros se habrían llevado a cabo en el Palacio del embajador de Portugal ante la Santa Sede, Almeida. Éste consideró que la prisión de Pagliarini vulneraba la inmunidad diplomática. A pesar de los intentos portugueses por obtener el perdón, pasó un año en la cárcel y fue condenado a siete años de galeras. No consiguió el perdón papal hasta $1762^{32}$.

\section{En la correspondencia, el Secretario Torrigiani refería así este suceso:}

«El señor cardenal Orsini recibió orden del señor marqués Tanucci para hacer partir inmediatamente para Nápoles al librero Pagliarini. Lo llevó a cabo Su Excelencia con altísimo misterio y secreto, y en una calesa suya, habiendo buscado personalmente la licencia para los caballos y de noche, lo sacó del Palacio Farnese. Esto lo llevó a cabo Nápoles tras una carta que envió la corte de Lisboa a su ministro en Nápoles... Sería extraño que el señor marqués no ayudara en algo que disgustase a nuestra corte, pero lo peor es que ha hecho de esto un triunfo... Considerado bien el asunto, nada importa a Nuestro Señor que Pagliarini haya salido de Roma y que se le haya colmado de honores y dinero por la Corte de Portugal ${ }^{33}$, porque si lo hubiese considerado un sujeto importante, no lo habría dejado escapar de su mano cuando lo tenía en su poder ni lo habría agraciado de la pena a la que le habían condenado los jueces. No se puede sin embargo negar que un príncipe que corre a proteger a un súbdito de otro príncipe, que ha tenido la desgracia de merecer su resentimiento, no muestra preocuparse mucho de su amistad, y que un ministro que apoya

30. ASV, Op. cit. La Bula In Coena Domini debe su nombre a la prescripción que estuvo en vigor durante siglos de darle lectura solemne en todas las iglesias con ocasión de la festividad del Jueves Santo. Ese día, durante los oficios litúrgicos, se informaba a los fieles de la relación de los principales delitos castigados con excomunión y reservados a la autoridad pontificia. Cit. en DE LA HERA, A. «La bula In Coena Domini» en MARTINEZ RUIZ, E. (Ed.): Dogmatismo e intolerancia, Madrid 1997, pp. 71-87.

31. ASV, Op. cit, cifra del 5 de noviembre de 1761.

32. VENTURI, F. Settecento riformatore, tomo II, Turín, pp. 26-27.

33. Efectivamente, tras ir a Nápoles, recibió una pensión de la corte de Portugal, instaló su negocio de impresión en Lisboa (1763) y se especializó en traducir documentos en italiano para el gobierno portugués. Vid. MILLER, Samuel J.: Portugal and Rome, c. 1748-1830. An aspect of the Catholic Enlightenment, Roma, 1978, pp. 132-133. 
con toda su autoridad esta protección, da a conocer que no pone gran atención en cultivar una buena correspondencia... Sobre todo, insista usted [el nuncio en España] en la insolencia del que ha publicado o ha impulsado publicar que en el ajuste futuro que se hará entre la Santa Sede y la corte de Portugal bajo los auspicios y la mediación de un rey español, tendrá que aparecer como condición preliminar el señor Pagliarini ${ }^{34}$. Estoy seguro de que Su Majestad Católica no podrá contener su desdén al escuchar una petulancia del género, y que cuando llegue el momento de tratarse más profundamente el referido acuerdo, no querrá ni oír una condición semejante, aunque viniese pedida, pero por si acaso usted vierta de forma preventiva las semillas capaces de hacerla recibir con indignación» ${ }^{35}$.

Pero no parece que el nuncio Pallavicini obtuviera gran éxito con sus peticiones. No hay más que leer el siguiente párrafo de una carta fechada a finales de marzo de 1762:

«Me escribe Vuestra Ilustrísima... que el señor Wall no se encargará de llevar nuestras quejas a Su Majestad Católica sobre lo ocurrido en Nápoles con el librero Pagliarini, si antes no le da usted una representación por escrito... Me parece que con dicho ministro [Wall] serán inútiles también las representaciones por escrito, ya que no veo que se dé ninguna respuesta a la que usted entregó sobre las "Reversales" de la investidura de Nápoles... Le repito la orden para mantener alguna reunión» ${ }^{36}$.

En materia de beneficios, el panorama era desolador para la Santa Sede. Los obispos que demostraban mayor obediencia a Roma sufrían la persecución del gobierno napolitano. Caso ejemplar fue el del obispo de Marsi:

«Sobre las violencias que se hacen a los obispos, puede ser convincente argumento la orden dada a monseñor obispo de Marsi para dar la aprobación en dos meses, bajo pena de pérdida y secuestro temporal del obispado, a una de las reales provisiones de las abadías sobre las cuales sepretende y se juzga juntos el real patronato. Una orden semejante se amenaza también sobre el obispo de Sarno por una cuestión parecida. Su Santidad ha creído que no debía callar y por eso, ha ordenado a monseñor nuncio dar a la Regencia una representación con el objeto de procurar una solución a tanto desorden, que nace de la siniestra interpretación del concordato al hacerse los tribunales napolitanos los jueces de la subsistencia de los reales patronatos, y al no cuidar la inmemorable y antiquísima posesión de los libres beneficios de la Sede Apostólica...» ${ }^{37}$.

34. No hay que olvidar que en este momento, las relaciones entre Roma y Portugal no existían. La ruptura tuvo lugar en 1760, con la expulsión del nuncio Filippo Acciaiuoli Se veía posible por parte de Roma, y no tanto de Portugal, la llegada a un acuerdo con la intervención del rey de España como mediador.

35. ASV, Segreteria di Stato, Spagna, vol. 431, cifra del 18 de febrero de 1762. Traducción propia.

36. ASV, Ibidem, cifra del 25 de marzo de 1762. Traducción propia.

Sobre este propósito, es interesante observar lo que escribió Tanucci: «Credendo che dispiacerebbe in questo tempo alla Corte di Spagna, che questa [Nápoles] facesse tratti d'amicizia verso quella di Portogallo, hanno dato ordine al nunzio che esageri quel che io, e Orsini abbiamo fatto sul fatto di $\mathrm{Pa}-$ gliarini in ossequio del re di Portogallo. Ma l'invettiva del nunzio è stata dal ministro di Spagna ricevuta prima con riso, poi con disprezzo, finalmente con una ggridata per l'ardire di dir nelle corte di Spagna mal di quella di Napoli» (cit. en MAIORINI, M.G. Op. cit., Tanucci a Bottari, Caserta, 27 de abril de 1762, p. 93 ).

37. ASV, Ibidem, cifra del 8 de abril de 1762. Traducción propia. 
En realidad, lo que le ocurría al obispo de Marsi Benedetto Mattei (1721-1776) era que se había negado a instituir al abad Quercia presentado por el rey en la abadía de Scurcola, declarada de Patronato Real antes de 1759. Su disputa con la jurisdicción real no acababa aquí:

«Il vescovo di Marsi, spalleggiato da Roma, vuole usurpareli benefizi di patronato feudale delli stati di Celano e Piscina in vigore d'una clandestina transazione fatta tra Roma e il vescovo, senza essere inteso il Re e il governo regio di quel tempo ${ }^{38}$.

Roma intentaba poner fin a estas disputas, pero sin resultados positivos. Como afirmaba Torrigiani:

«Y sobre este asunto, siguiendo el informe de las continuas ofensas, agravios y angustias que se reciben de allá [Nápoles], en primer lugar debo señalarle que nada hemos sacado de la representación dada sobre los reales patronatos. Se nos ha respondido por escrito que el Rey la habia visto y considerado, después personalmente se ha hecho entender al Nuncio que todo era una usurpación de Roma y que pudiendo constatar la real fundación de alguna abadía, ésta debía ser de disfrute real, a pesar de alguna contraria posesión, acto o concordato y que nada podía perjudicar a los derechos inherentes a la Corona, como se pretenden que sean los patronatos... El hecho está en que son inminentes los secuestros, y otras amenazas a los obispos que rechazan dar la institución a las provisiones reales» ${ }^{30}$.

Cada vez la situación entre Nápoles y la Santa Sede se hacía más tensa. La publicación en Nápoles de un decreto en el que se ordenaba «che non si devano alla Camera Apostolica di spogli dei benefizi di patronato regio e feudale, e de quelli di rendita sotto a 30 scudi d'oro» fue la gota que colmó la paciencia de Roma. Torrigiani en carta al nuncio Pallavicini de 27 de mayo de 1762, comentaba el asunto en los siguientes términos:

«Vuestra Ilustrísima sabe el mérito y la categoría de toda la controversia por el spoglio composto. Tras su partida de Nápoles, y en los últimos días de su nunciatura, en que usted entregó una memoria al señor don Giulio d'Andrea, y una semejante entregué yo mismo al señor duque de Cerisano, relativa a este asunto, y que produjo la suspensión de la resolución contraria a los derechos de la Cámara Apostólica, no se había hablado más de esta cuestión... Ahora, de repente, sin ningún precedente aviso,... se ha emitido un despacho en que se ha exento del spoglio composto a todos los beneficios del Patronato real o feudal y a todos los que no sobrepasen la renta de 30 ducados de oro...» ${ }^{\text {t0 }}$.

Esta acción napolitana encrespó los ánimos romanos. Y si todo esto no era suficiente, aparecieron dos órdenes que en nada ayudaron a apaciguarlos. El propio Torrigiani lo comentaba así en agosto de 1762:

«... esta especie de pragmática fue dirigida a todas las guarniciones del reino por la Cámara Real, no ya por orden de la Regencia, donde se ha tomado esa exorbitante resolución, sino del propio marqués Tanucci con la inteligencia del monarca. Yo me imagino

38. MAIORINI, M.G. Op. cit., Tanucci al Rey Católico. Nápoles, 24 de agosto de 1762, p. 345.

39. ASV, Ibidem, cifra del 20 de mayo de 1762. Traducción propia.

40. ASV, Ibidem, traducción propia. 
que la distribución en limosnas a los pobres del país del tercio de las rentas de los beneficios eclesiásticos, insinuada ahora a los beneficiados, como prueba de su cumplimiento queda ahora irrealizada, en breve cambiará su naturaleza y vestirá el aire de orden, con los ecónomos reales que secuestrarán el tercio de los beneficios, para hacer después lo que la Corte quiera... Otra injustísima orden fue dada por el marqués Fraggianni a todos los provinciales de los regulares. Se les ha notificado no ejecutar las órdenes de los Superiores Generales de Roma, en las cuales se dé alguna medida para la buena disciplina de los religiosos, si antes no eran exhibidas y revisadas por él las cartas que llevan dichas medidas. Usted podrá ver qué vuelco de la disciplina es éste, qué audacia se añade a los frailes disolutos para recalcitrar, qué injusticia de los tribunales laicos, pretendiendo usurpar la autoridad de conocer las cosas más internas de los regulares y finalmente, qué subversión se hace de cada ley eclesiástica para desacreditar y humillar al sacerdocio ${ }^{4 i}$.

Roma, por supuesto, no dejó de mover todos los hilos para defenderse. En una carta de 19 de agosto de 1762, Torrigiani afirmaba:

«Por segura, aunque secreta noticia, he sabido que en el pasado [correo] ordinario, el señor príncipe de San Nicandro escribió al monarca [español] una fuerte carta contra el marqués Tanucci, aprovechando la oportunidad de la última pragmática sobre las limosnas,... fue publicada... cuando el mismo príncipe estaba ausente porque otra vez que se había propuesto una tan extraña medida se había opuesto válidamente... A esta carta para Su Majestad Católica se supone que ha añadido otra para su confesor. Nuestro Señor quiere aprovechar esta ocasión para avanzar él también sus representaciones contra tantas violencias que en el Reino de Nápoles desde hace poco tiempo se han hecho contra la jurisdicción eclesiástica y contra la Santa Sede. En otro ordinario, transmitiré todo a Vuestra Ilustrísima. Entretanto, vaya usted investigando con destreza y sin mostrar que ha sido informado, la impresión que ha hecho en el ánimo de Su Majestad el recurso del príncipe de San Nicandro. El medio del confesor sería ideal para efectuar algún hallazgo... los desórdenes han llegado al colmo. En resumen, con sus conversaciones trate de reforzar el recurso del señor príncipe de San Nicandro y procure también disponer los ánimos para escuchar con más voluntad las quejas del Santo Padre.... ${ }^{42}$.

Las últimas disposiciones de Nápoles, es decir la decisión sobre las limosnas, los «spogli», la cuestión formal de la investidura ${ }^{43}$ colmó la paciencia de la Santa Sede y le empujaron a enviar en agosto de 1762 una protesta formal a Madrid:

«Por tantos agravios que sufre en el Reino de las Dos Sicilias la religión, la Iglesia y la autoridad del Sumo Pontífice, estando su ministerio apostólico muy conmovido, representa todo a Su Majestad Católica en el compendio de todo y en la carta adjunta implora de la misma majestad un pronto remedio... Vuestra Ilustrísima informará al señor Wall, mostrándole las copias de ambos y le rogará obtener de Su Majestad una audiencia particular en la cual usted pueda presentar al rey los originales... Su Majestad Católica debe

41. ASV, Ibidem, traducción propia. Cifra del 12 de agosto de 1762.

42. ASV, Ibidem, traducción propia.

43. Los cambios introducidos por Tanucci se pueden considerar el primer intento de eliminar definitivamente el problema del vasallaje del reino de Nápoles respecto al Estado Pontificio. Las reglas de la investidura establecían un tributo anual a pagar al Pontífice con el rito de la chinea. En 1776, Tanucci consiguió abolir la ceremonia de presentación de la chinea. 
estar del todo ignorante... refuerce usted con su voz las paternales amargas quejas de Su Santidad expuestas en su carta y la gravedad e injuria de los agravios que en el compendio están descritos... ha escrito Su Santidad el breve anexo al padre confesor del rey para animarlo a cooperar por su parte en tan loable empresa» ${ }^{44}$.

Recurrir a España para frenar a Nápoles era una acción lógica para Roma. El Memorial que envió el Papa contra «le molte novità pregiudiciali alla giurisdizione ecclesiastica e all'interesse della Santa Sede, dei vescovi e degli ecclesiastici in generale» ${ }^{45}$ vino a ser la «summa» de todas las injusticias y violaciones del Concordato que la Sede Apostólica lamentaba sufrir en el Reino de Nápoles.

Era un documento recogido por el nuncio, monseñor Locatelli, y unido a un breve que el Papa envió simultáneamente al joven rey de Nápoles y a su padre, Carlos III de España. Constituyó éste, pues, el punto más alto de fricción en el conflicto de las Cortes napolitana y romana. Además, fue el momento a partir del cual se empezó a percibir una inflexión en la lucha jurisdiccional llevada a cabo por Tanucci y sus partidarios, principalmente Fraggianni y De Marco.

Tras la cuestión del Catecismo de Mésenguy, los contrastes con la Iglesia quedaban abiertos por viejas cuestiones (circular a los obispos sobre la bula In Coena Domi$n i$, abadías de Patronato Real). Pero se abrían nuevos frentes de conflicto como los beneficios eclesiásticos, gozados en el reino por los prelados extranjeros naturalizados napolitanos, que llevó a la circular sobre las limosnas y a la pragmática de los spogli.

Todos estos hechos preocupaban a Torrigiani, que estaba a la espera de la respuesta que el joven rey Fernando y su padre debían dar a los dos breves enviados por Clemente XIII. La contestación de los reyes no se hizo esperar. Antes lo hizo Fernando. Torrigiani escribía ${ }^{46}$ :

«Por lo que he podido entender por su cifra del 21 pasado... recojo que Su Majestad Católica se informará sobre las cosas de Nápoles por las cuales le hemos hecho recurso, no solamente por parte de la Regencia sino también por alguna otra persona y además, serán también allí consultados otros sujetos... Entretanto, yo le incluyo para su información la carta que el rey de Nápoles ha respondido a Nuestro Señor. Observará usted que se hace autor al rey de España mientras estaba en el trono de las Dos Sicilias de los principales asuntos sobre los cuales se ha formado nuestro compendio. Esto mismo se ha repetido personalmente a monseñor nuncio por el ministerio de Nápoles. Pero es cosa fácil hacer ver lo contrario porque muchos de los referidos asunto o son nuevos o si de otros fue el rey de España el autor o no creía que pudiesen producir tan perniciosos efectos las órdenes que dio, o han sido extendidas más allá por la Regencia».

La situación llegaba a su máxima tensión. Y Torrigiani iba a utilizar todas sus armas tanto en Nápoles como en la corte española. Las instrucciones que envió al nuncio Pallavicini dejaban ver sus propósitos: Tanucci y sus colaboradores debían ser derrotados.

44. ASV, Segreteria di Stato, Sezione Spagna, cifra del 26 de agosto de 1762. Traducción propia.

45. MINCUZZI, R. Op. cit., p. 49.

46. ASV, Segreteria di Stato, Sezione Spagna, vol. 431. Cifra del 14 de octubre de 1762. Traducción propia. 
El estudio de la correspondencia del Secretario de Estado Vaticano con el nuncio apostólico en España ofrece un gran interés a la hora de configurar las tensas relaciones entre Roma y la Corte napolitana en este período.

Nápoles tenía una conexión inevitable con España por los acontecimientos del momento y el anterior reinado de don Carlos. Y Nápoles representaba uno de los más serios obstáculos ante la lucha de la Santa Sede por conservar lo que consideraba sus «derechos inalienables e inherentes». Éstos se veían dañados por la política regalista llevada a cabo por los gobiernos, que si bien no cuestionaba la supremacía del Papa como jefe espiritual, sí se esforzaba por incrementar la autoridad del soberano en su territorio.

Torrigiani, en su lucha particular con Tanucci, consideró siempre a la corte española como la única mediadora en un conflicto que estimaba, dado el talante del ministro napolitano, difícil e irremediable. Los acontecimientos posteriores no hicieron más que darle la razón. Las relaciones de Nápoles con la Santa Sede siguieron siendo problemáticas, si bien no se debe olvidar que las reformas napolitanas nunca llegaron a cumplirse según los deseos de Tanucci. Ya desde el principio se sintió desencantado y hastiado de tener que luchar prácticamente en solitario contra los prejuicios y los temores que todavía inspiraba el poder de Roma. 